referred to in Rule 6), the Library Committee shall be at liberty to purchase another copy, the cost to be charged to such member, who shall not be allowed to borrow another book until the sum thus expended shall have been paid.

8. All communications should be addressed to "The Librarian, Royal MedicoPsychological Association, I I, Chandos Street, Cavendish Square, W.r."

\title{
Circulation of Journals
}

The following journals are available at the Library :

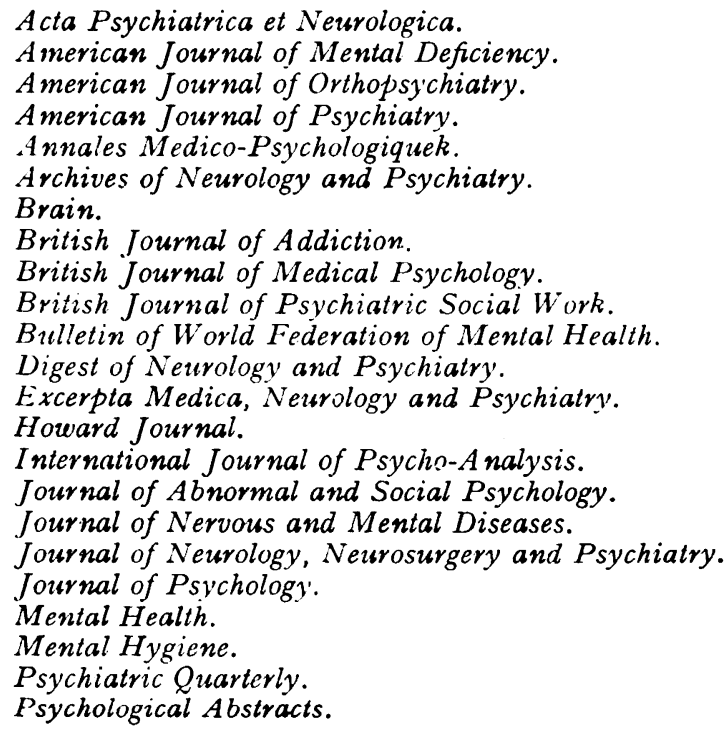

\section{NOTICES BY THE REGISTRAR.}

Bronze Medal and Prize.

Dissertations for the Association's Bronze Medal and Price should be forwarded to reach the Registrar not later than April 30 for each year.

\section{Divisional Prizes.}

Papers certified as eligible for this competition must be forwarded to reach the Registrar not later than April 30 for each year.

\section{Gaskell Medal and Prize.}

The examination for the Gaskell Medal and Prize is held annually in May. An entrance fee of $£ 3$ ss. is charged, returnable to bona-fide candidates. Entrance fees are due by March $3 \mathrm{I}$.

\section{The Diploma in Psychological Medicine.}

The examination for the Association's Diploma in Psychological Medicine will be held annually in May and November. The examination comprises :

Part I (a) Psychology.

(b) Anatomy and Physiology in their relation to nervous and mental diseases.

Part II (a) Psychiatry.

(b) Psychosomatic Medicine and Neurology.

Fees are eight guineas for Part I and twelve guineas for Part II, and are payable to the Registrar, R.M.P.A.

Prospective candidates should apply to the Registrar at least two months before the examination at which they wish to sit.

Full particulars may be obtained from the Registrar, R.M.P.A., II, Chandos Street, London, W.I, on receipt of stamped, addressed envelope. 